\title{
A Sharpe-ratio-based measure for currencies
}

Javier Prado-Dominguez, Universidade da Coruña

Carlos Fernández-Herráiz, CAIA

\begin{abstract}
The Sharpe Ratio offers an excellent summary of the excess return required per unit of risk invested. This work presents an adaptation of the ex-ante Sharpe Ratio for currencies where we consider a random walk approach for the currency behavior and implied volatility as a proxy for market expectations of future realized volatility. The outcome of the proposed measure seems to gauge some information on the expected required return attached to the "peso problem".
\end{abstract}

\section{Keywords}

Sharpe Ratio; peso problem; carry trade; currency strategies.

\section{JEL Codes}

G11; G13; G15; G17. 


\section{Introduction}

The reward to variability ratio has been around for nearly 40 years since the seminal work by Sharpe (1966). Since his paper, the so called Sharpe ratio spawned various performance measures, including several adaptations of the ratio, which offer different flavors of the risk reward relationship. The success of the ratio is rooted in the combination of two opposing but complementary concepts: risk and return. The ratio is always stated as the excess return of a portfolio or strategy per unit of risk handled. It is a simple but effective measure of how well rewarded are the risks taken if some assumptions about markets and investors are made. The ratio could help selecting among strategies or portfolios.

When an investor makes use of the Sharpe ratio, she must pay attention to the various assumptions involved in the measure. The ratio implies that mean and standard deviation for one period are sufficient statistics for evaluating the attractiveness of a portfolio. But comparisons based on the first two moments of the distribution do not take into account possible differences among portfolios in other moments. In fact, Goetzmann et al (2002), offer a "sharp" analysis of the issue, proving that the distribution of returns that maximizes the ratio is the one with significant third and fourth moments. Those moments imply fat left tails (big unexpected losses more frequent than expected if the returns followed a normal distribution), and also a higher concentration of returns around the expected return of the distribution (offering a false sensation of security to investors).

The field of currency trading is well aware of this kind of phenomenon. It is one of the main explanations adduced to justify the conundrum of the forward puzzle. Other common explanation for the forward puzzle is the "peso problem", see Fama (1984). The "peso problem" is another conundrum on its own. It states that if an investor finds an asset with a potential excess return, she may suspect there is a risk behind a classic assumption of the modern portfolio theory. And if she is not able to find where the potential risk is hidden, then it is probable that the market is pricing a "peso problem": a low frequency but massive negative result. The original example was apparently named in this way by Milton Friedman in the seventies, see Sill (2000). The Mexican peso was offering a spread return versus the dollar risk free rate even though a policy of fixed exchange rates was in place since a long time ago between the US Dollar and Mexican Peso. After the late seventies peso devaluation, the saying was that the spread between the currencies interest rate returns was the market price for the potential disruptive but unexpected devaluation event. Again, the "peso problem" advances a distribution of returns with fat tails and a high concentration of returns around the average.

Currency crashes, the peso problem and potential investor biases are the more accepted explanations of the failure of the uncovered interest rate parity. Even though it is not still possible to find a consensus among researchers regarding the origin of the currency risk premium, it is difficult to simply deny the existence of such a premium. The analysis of naïve carry trade strategy returns over the last thirty years shows the existence of a persistent differential return. More refined strategies offer even better and more difficult to explain spread returns. See Jordá and Taylor (2009), Clarida et al (2009), Menkhoff et al (2014), Ilmanen (2014), to name a just a few.

As a final comment, John Maynard Keynes (1924) noted a long time ago that the interest rate parities may only hold, and it is even uncertain, if we expect no capital controls, perfect convertibility, neither sovereign risk nor country risk, and other different assumptions. But if the investor finds riskier countries or riskier currencies, whatever the definition of riskier we employ, we should expect excess expected returns for a currency strategy and positive risk premiums for the risky currency investments. So the assumption of zero excess return should not hold, and there is little sense in looking for the accomplishing of the uncovered interest rate parity in every possible currency pair. That is why a reflection regarding the use and 
adaptation of the Sharpe's reward to variability ratio to currency strategies could lead to a further understanding of the matter.

In section 2 we define our Sharpe Ratio adaptation for evaluating currency expected returns and risks. Section 3 shows two examples of potential Latin American currencies with "peso problems" embedded and the information offered by our adaptation of the Sharpe Ratio. The paper ends with some conclusions and suggested paths for related research.

\section{A sharpe-ratio-based measure for currencies}

The raison d'être of the ratio, as stated with the very same words by Sharpe (1994), is the analysis of zero investment strategies. In our view, strategies involving currencies, and particularly that carry trade, are appropriate examples of that way of thinking about differential returns. A currency is always quoted in relation to other currency. And the strategy of running short currencies with the lower rate and long currencies with the higher rate is a perfect zero investment one. The traditional building blocks of this strategy would be a short leg, borrowing money in the currency with the lower rate and a long leg, converting the proceeds into the investment currency and investing them at the higher rate.

We will try to express a natural way of transposing the risk to variability ratio into the field of a simple currency strategy. First we will define the numerator of the ratio, the differential return, which will be called from now on indistinctly as excess return or time varying risk premium; or just the risk premium.

The excess returns for the period $t$ to $t+1, x s_{t+1}$, are defined as follows:

$$
x s_{t+1}=\left(i_{t}^{*}-i_{t}\right)+s_{t+1}-s_{t}
$$

Where $i_{t}^{*}$ is the one period interest rate return for the investment currency and $i_{t}$ is the investor currency or risk free currency - we may consider these two definitions as equivalent for this exercise. And where $s_{t+1}$ and $s_{t}$ are both the log of the exchange rate at those periods, expressed as units of investor currency (the risk free currency) per investment currency. When we represent the exchange rate in this manner, it is quite clear for the reader that an increase in the exchange rate implies an appreciation of the investment currency, also implying good news for a potential investor. It is equally possible to think about exchange rate the other way around, but we favored that representation for the sake of clarity. If there is an appreciation of the investment currency, the investor receives the interest rate spread for the period, but also the appreciation of the currency. Both things sum up to the left hand side of the equation, $x s_{t+1}$, the excess returns.

As stated, when the investment period comes to an end, the realized return for the investor is the sum of both the interest rate spread and the variation in the exchange rate. Nowadays, it is convenient to realize that the effect of the exchange rate could be positive, negative, or even zero.

If we were to follow Sharpe in the definition of the ex post or historical ratio, we would think about averaging the $x s_{t+1}$ observations for the T period so:

$$
\overline{x S}=T^{-1} \sum_{t=t+1}^{T} x s_{t+1}
$$

We would then compute the standard deviation of the excess returns, $\sigma_{x s}$, and define the ratio as:

$$
S_{h}^{*}=\frac{\overline{x s}}{\sigma_{x s}}
$$

And finally, for purposes of standardization, take the annualized version of the ratio multiplying by the square root of the number of periods in a year. 


$$
S_{h}=\frac{\overline{x s}}{\sigma_{x s}} \sqrt{t_{y}}
$$

Where $t_{y}$ is the number of periods in the year, being 12 for monthly excess returns, 52 for weekly excess returns, and so on and so forth. That would be a correct transposition of the historic Sharpe ratio for currency investing ex post analysis. Unfortunately, this may be a worthless exercise if we do not offer an answer to the definition of the ex-ante risk to variability ratio.

The ex-ante Sharpe Ratio would be helpful for making investment decisions if the proper assumptions are respected, but is also the key to move the discussion towards a theoretical approach.

So, what should be the definition of the ex-ante risk to variability ratio in a context of currency investing? Let us begin with the more general formulation:

$$
S_{t}=\frac{E_{t}\left(x s_{t+1}\right)}{E_{t}\left(\sigma_{x s}\right)} \sqrt{t_{y}}
$$

Where the ratio is built including the expected excess return in $t+1$ conditioned on the information known at $t$ in the numerator. The denominator will be the expected volatility of the excess return again conditioned on the information known at $t$.

We invoke the former definition of excess returns for the period $t+1$. But now we will express the expected return based on the information known in t. So the expected excess return will be:

$$
E_{t}\left(x s_{t+1}\right)=\left(i_{t}^{*}-i_{t}\right)+E_{t}\left(s_{t+1}\right)-s_{t}
$$

As a matter of fact, interest rates for both currencies are known at $t$, and the currency spot rate at $t$ is also known. But an expression of the expected nominal exchange rate in $t+1$ is needed if we want to draw an informed decision. There are different ways of coping with this issue, and the literature has developed appealing alternatives. For a promising proposition on currency valuation and predictability see Menkhoff et al (2014).

As noted by Meese and Rogoff (1983), nominal exchange rates are difficult to predict. They are so difficult to predict that even a random walk does a decent job compared to some structural models of exchange rates. Since their seminal but discouraging paper, a lot of work and some progress have been made on the predictability of currencies. Sarno and Taylor (2003) offer an extensive review and cover these and other topics on currencies. That said, even today, the random walk seems the hardest benchmark for every new potential currency model. See Rossi (2013) for a review of factors, models and results.

We could assume that the nominal exchange rate in our model is well represented by a random walk. Then, we could write that:

$$
s_{t+1}=s_{t}+e_{t}
$$

Where $e_{t}$ is white noise. If we take expectations on $\mathrm{t}$, note that:

$$
E\left(s_{t+1}\right)=s_{t}
$$

Assuming that the spot nominal rate follows a random walk, the expected currency excess returns simplify to:

$$
E\left(x s_{t+1}\right)=\left(i_{t}^{*}-i_{t}\right)
$$

The random walk simplification is used sometimes in the currency trading models of the industry, as IImanen (2014) briefly notes. Interestingly, the expected excess return ends up as the spread between the fixed return offered by the investment currency and the fixed return offered by the risk free currency. This naïve model of expected returns would suggest selecting the investing currency with the highest 
interest rate spread in order to gain access to the highest expected return. Unfortunately, it is well known that spreads entail risks, and high spreads may imply high expected risks.

In a freely convertible currency, and imposing a no arbitrage framework, expected currency volatility should also give the investor some ex-ante information about the potential risks of the carry trade strategy. It is sometimes possible to model volatility, and even to obtain an outlook of its next developments. There is a huge literature on this issue, but the reading of Poon and Granger (2003) may offer an extended critical survey on the matter. Drawing on their conclusions, it seems that implied volatility extracted from quoted options on exchange rates does a decent job in predicting expected volatility. It usually beats even complex $\mathrm{ARCH}$ family models and other suggested procedures.

A potential proxy for the expected excess returns volatility could be the implied at the money volatility. The implied volatility is available as the volatility expected for an asset which is "implied" in the quotations of the "at the money" options on the asset. Taking the implied volatility, $v_{t}$ as the representation of the expected volatility, we will say that:

$$
E\left(\sigma_{x s}\right)=v_{t}
$$

Finally we are able to construct the proposed ratio for our model of currency investing, so the ex-ante return to variability ratio may be:

$$
S_{t}=\frac{\left(i_{t}^{*}-i_{t}\right)}{v_{t}} \sqrt{t_{y}}
$$

All variables were previously defined, and we prefer to keep the annualized formulation following Sharpe (1994) once more. If we decide to use nominal year interest rates and annualized implied volatility, the ratio simplifies to:

$$
S_{t}=\frac{\left(i_{t}^{*}-i_{t}\right)}{v_{t}}
$$

The proposed Sharpe Ratio shows the interest rate differential return per unit of implied volatility, and do not try to make a judgement regarding the future path of the investment currency. In fact, the ratio assumes that the currency follows a random walk with no drift.

Actually, ex-ante judgements about future currency outcomes are embedded into the implied volatility data. Due to the potential predictability of future currency volatility patterns, the implied volatility data introduces the market view on potential future risks. But sometimes, for reasons that could be rooted in the ideas presented on the next paragraphs, a disconnection between risk expectations based on volatility and interest rate differentials between currencies may arise. This is a key question to consider because, at the end of the day, the interest rate spread is another way of looking at currency risks. In fact, interest rate spread is the risk premium of the asset: The investment currency for our purposes.

We will make a first empirical approach coming back to the currencies where the "peso problem" was first noticed: the Latin American currencies.

Ex-ante currency Sharpe Ratio and selected Latin American Currencies: Seeking potential peso problems

As a first approach towards the use of the proposed currency Sharpe ratio for detecting peso problems, we will look at two of the Latin American (Latam) currencies with the highest interest rate spreads versus the dollar during the period of study. The currencies are the Brazilian Real (BRLUSD) and the Argentinean Peso (ARSUSD).

We collected daily data for both currencies since January 2007 until March 2015 from the Bloomberg Professional LP database. The data starts well before the 
beginning of the last bear market in risky assets. In particular, naïve carry trade strategies suffered severe losses during the period, concentrated in the second half of 2008.

The currencies evaluated are the Brazilian Real (BRLUSD) and the Argentinean Peso (ARSUSD) versus the US Dollar. The series include the one-month-deposit interest rate for each currency including the US Dollar; the implied at-the-money onemonth volatility for each currency, and the currency spot return for each month.

We built the monthly ex-ante reward to variability ratios for each currency (ARSUSD_SR and BRLUSD_SR) using the proposed measure in section 2. The main descriptive statistics for the series of Sharpe ratios are shown in Table 1, and the evolution of the ratios during the period are shown in Graphs 1 and 2.

Table 1. Descriptive statistics for the ex-ante Sharpe Ratio series (January 2007 to March 2015)

\begin{tabular}{c|cc}
\hline & ARSUSD_SR & BRLUSD_SR \\
\hline Mean & 1.97 & 0.7 \\
Median & 1.74 & 0.69 \\
Maximum & 7.12 & 1.31 \\
Minimum & 0.23 & 0.26 \\
Std. Dev. & 1.14 & 0.24 \\
Skewness & 1.26 & 0.49 \\
Kurtosis & 5.89 & 2.49 \\
& & 5.17 \\
Jarque-Bera & 60.84 & 0.075446 \\
Probability & 0.000000 & \\
& & 69.5206 \\
Sum & 195.3151 & 5.727 \\
Sum Sq.Dev. & 128.3374 & 99 \\
\hline Observations & & 99 \\
\hline
\end{tabular}

A quick look at the data shows an unusually high ex-ante risk to variability ratio for the Argentinean Peso (ARSUSD_SR). Average levels around 2 imply an expected 2 percent return per unit of implied volatility. Clearly investors demand a high interest rate return differential for investing in Pesos. The spread is so high that it obscures the level of volatility of the currency by 2 to 1 . These results were expected, because the Argentinean Peso has been seen as one of the toughest currencies to invest in the last fifteen years. The market is clearly pricing the ugly reputation of the ARSUSD as an investment.

Ex-ante Sharpe levels for the Brazilian Real (BRLUSD_SR) are clearly lower than the levels registered for ARS, but still high compared to Sharpe ratios offered by passive strategies. 
Graph 1. Ex-ante Sharpe Ratio for Argentinean Peso (ARSUSD_SR) (January 2007 to March 2015)

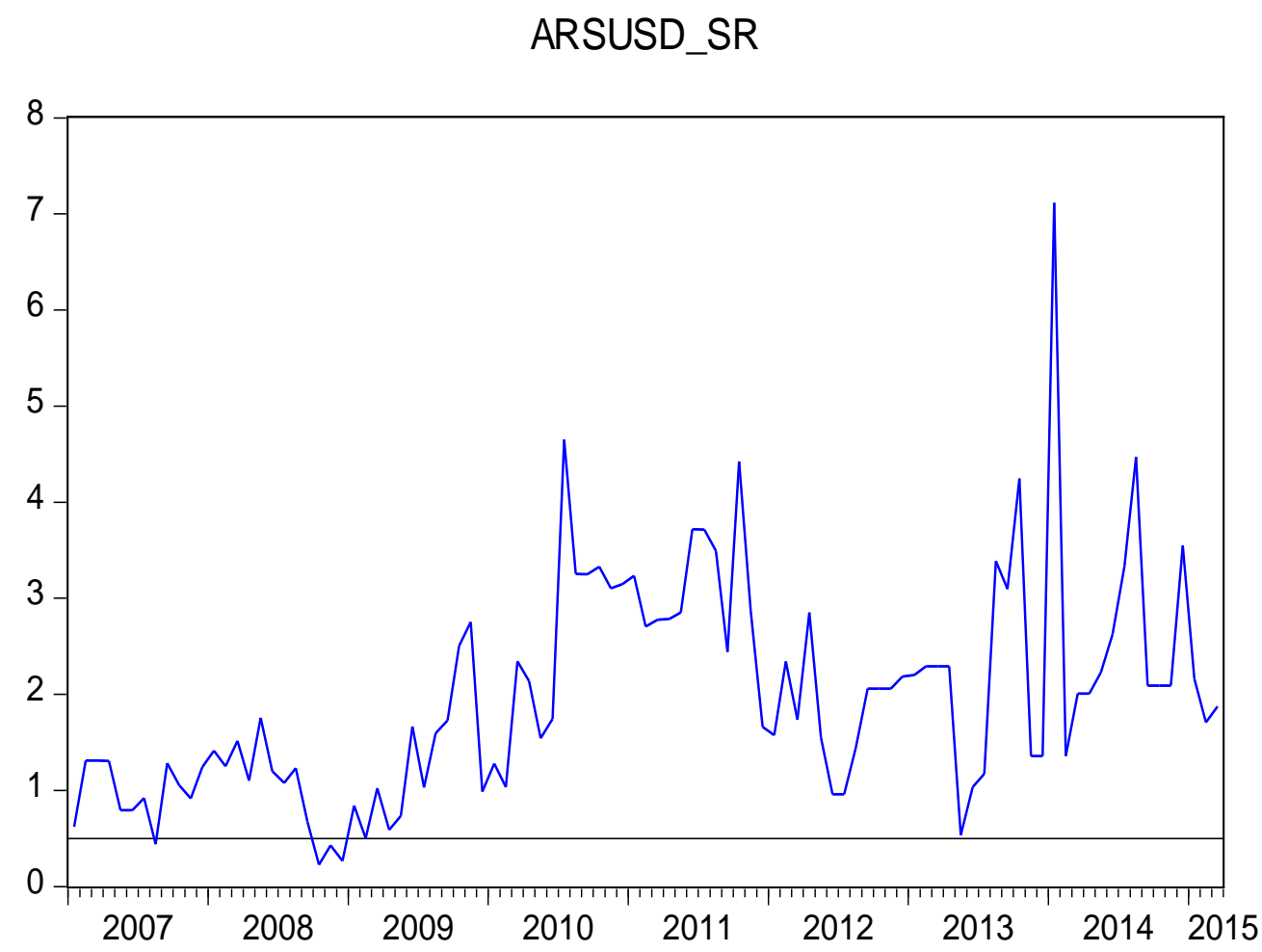

Graph 1 uncovers a demanding Sharpe ratio for the Argentinean Peso during the period. For illustrative purposes, we drew a line at the 0.5 Sharpe Ratio level. Sharpe Ratios of 0.5 or between 0.3 and 0.5 are typical levels for bechmarking passive strategies. We would say that an asset with an SR of 0.5 will offer five points of return per each ten points of volatility. The average level of the ex-ante Sharpe Ratio for the sample period is around 1.97. Levels of around 0.5 of ex-ante SR for ARS are only attained during stress periods and reverse quickly towards higher levels. See, for example, the valleys in the graph during the summer of 2007, the last quarter of 2008 , or the recent "tapering sell off" during may of 2013. Paradoxically, local events like the big depreciation of January 2014 appear more like volatile periods for the ratio, but also potentially well rewarded by interest rate differentials, offering the investor willing to ride the potential "peso problem" a reward for the high risk involved in the trade. 
Graph 2. Ex-ante Sharpe Ratios for Brazilian Real (BRLUSD_SR) (Jan-2007 to Mar-2015)

\section{BRLUSD_SR}

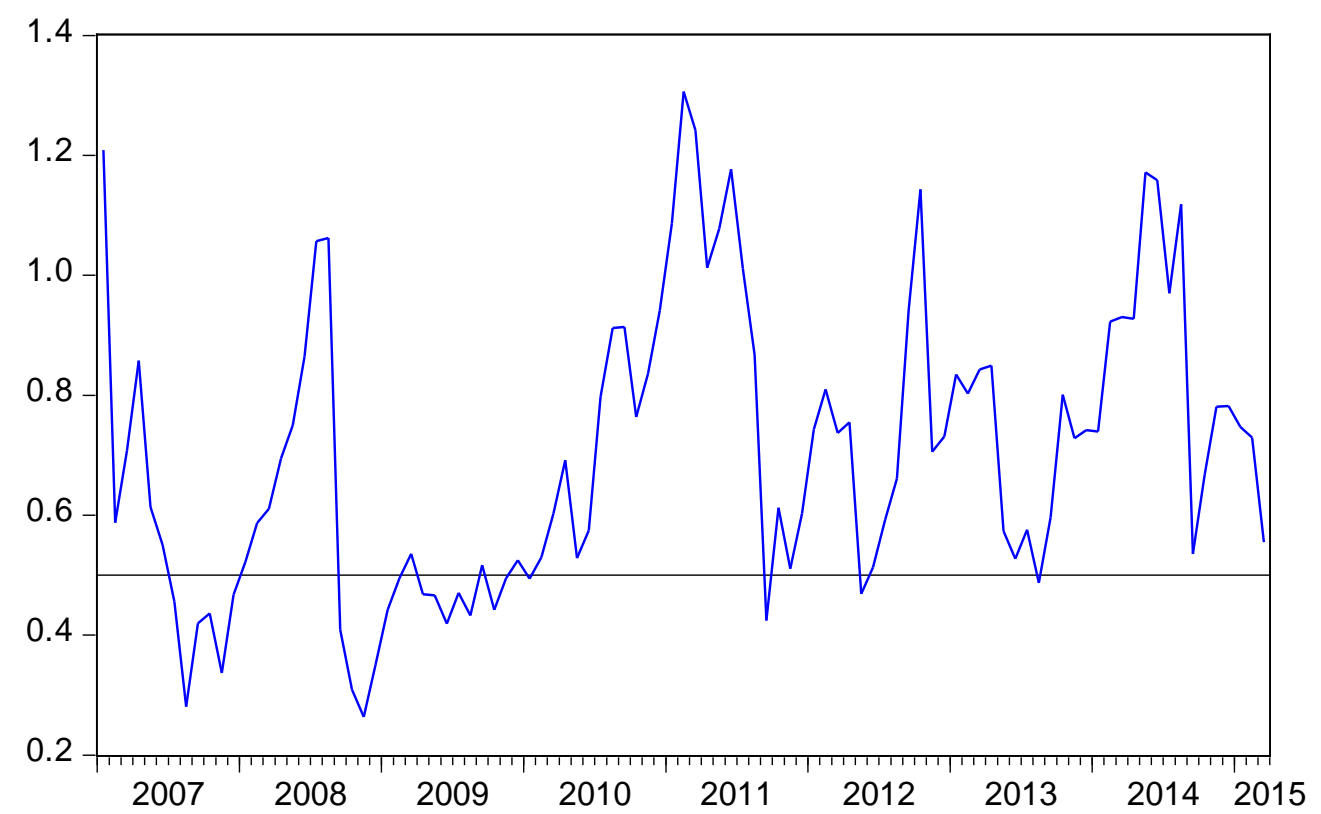

Although BRL investors require a less demanding Sharpe Ratio for investing in the currency during the period of study, Graph 2 shows that it is still well beyond the levels suggested for pure passive buy and hold strategies. The average value of the ex-ante Sharpe Ratio for the sample period is around 0,7 . Once more, the ratio may respond to potential peso problems embedded in the BRL investing strategy.

Stressed markets constitute inflection points, as we saw in the ARS case. The explosive volatility developments send the ratio down the elevator offering potential opportunities when the realized return is diluted due to exchange rate depreciation.

\section{Conclusion}

The reward to variability ratio is a commonly used measure of investment efficiency. The ex-ante version helps in debating theoretical questions. Our proposed adaptation to the ex-ante ratio for currencies leaves the potentially unpredictable currency movement apart, making use of the random walk hypothesis. We also consider implied volatility as a proxy for market expected volatility. Following that path, we are able to construct an ex-ante Sharpe Ratio including only known variables at time $t$. It that sense we do not introduce any expectation on the potential return of the spot currency, so we are explicitly not considering the uncovered interest rate parity projected return.

This way of presenting the ratio introduces a substantial bias towards selecting currencies with high interest spreads and low expected volatility, if we were to follow the classic approach of selecting strategies with the highest Sharpe Ratio. Perhaps this proposal of a Sharpe Ratio for currencies may also serve investors in a different way. The Ratio may uncover potential risks hidden in the structural relationship between expected volatility and expected interest rate spreads (the risk premium).

Once the ratio is built following those premises, a new and potentially interesting interpretation of the ratio arises. As we see it, a high risk premium per unit of implied volatility may signal a potential peso problem perception from market participants. 
This could open a new line of financial research that could assess the investment currency required return due to "peso problems", and even isolate it from other potential risk factors involved in currency investment strategies.

But, is it a behavioral problem or a rational response to future potential very negative outcomes? Both explanations may offer compelling arguments. We could conclude that high Sharpe Ratios signal a behavioral bias response for very negative past outcomes. It is easy to build the story for the currencies studied in the article. It could also be argued that these currencies require a high risk premium going forward due to a combination of political, macroeconomic and other risks.

\section{References}

Clarida, Richard, Josh Davis and Niels Pedersen (2009) 'Currency Carry Trade Regimes: Beyond the Fama Regression', NBER Working Paper No. 15523.

Fama, Eugene (1984) 'Forward and Spot Exchange Rates', Journal of Monetary Economics 14(3): 319-338.

Goetzmann, William, Jonathan Ingersoll, Mattew I. Spiege and Ivo Welch (2002) 'Sharpening Sharpe Ratios', NBER Working Paper No. 9116.

Ilmanen, Antti (2014) Expected Returns. West Sussex: John Wiley \& Sons.

Jordà, Oscar and Alan M. Taylor (2009) 'The Carry Trade and Fundamentals: Nothing to Fear but FEER Itself', NBER Working Paper No. 15518.

Keynes, John M. (1924) A Tract on Monetary Reform. London: Macmillan and co.

Meese, Richard and Kenneth Rogoff (1983) 'Empirical Exchange Rate Models of the Seventies. Do They Fit out of Sample?', The Journal of International Economics 14: 3-24.

Menkhoff, Lukas, Lucio Sarno, Maik Schmeling and Andreas Schrimpf (2014) 'Currency Value', Kiel institute for the World Economy, University of Kiel.

Poon, Ser-Huang and Clive Granger (2003) 'Forecasting Volatility in Financial Markets: A Review', Journal of Economic Literature 41(2): 478-539.

Rossi, Barbara (2013) 'Exchange Rate Predictability', CEPR Discussion Paper No. DP9575.

Sarno, Lucio and Mark P. Taylor (2003) The Economics of Exchange Rates. Cambridge: Cambridge University Press.

Sharpe, William F. (1966) 'Mutual Fund Performance', Journal of Business 39(1): 119-138.

Sharpe, William F. (1994) 'The Sharpe Ratio', The Journal of Portfolio Management 21(1): 49-58.

Sill, Keith. (2000) 'Understanding asset values: stock prices, exchange rates, and the "Peso Problem"', Federal Reserve Bank of Philadelphia Business Review September/October: 3-13. 